\title{
Mimese e crime em Adorno e Horkheimer: comentário sobre o "Fragmento de uma teoria do criminoso"
}

\author{
Gustavo Martineli Massola \\ Universidade de São Paulo
}

\begin{abstract}
Resumo
Este trabalho acompanha o pensamento de Adorno e Horkheimer na questão do crime e de sua punição, conforme expresso em "Fragmento de uma teoria do criminoso". Inicialmente, considera-se a importância de abordar o tema do crime na obra do Instituto de Pesquisa Social da Universidade de Frankfurt. Em seguida, o "Fragmento de uma teoria do criminoso" é analisado à luz dos conceitos de esclarecimento e de mimese. A idéia do criminoso como doente é considerada uma construção ideológica e, portanto, típica da sociedade burguesa. Por isso, não encontra mais justificativa racional em uma sociedade de economia monopolista. $\mathrm{O}$ conceito de mimese é considerado central para a compreensão do criminoso como doente e permite entender as mudanças enfrentadas pelo sistema penitenciário na sociedade posterior ao fascismo.
\end{abstract}

Palavras-chave: crime; mimese; escola de frankfurt; criminoso

\begin{abstract}
Mimesis and crime in Adorno and Horkheimer: coments on the "Fragment of a theory of the criminal". The article discusses the contribution of Adorno and Horkheimer in the issue of crime and its punishment, according to "Fragment of a theory of the criminal". First, considers the importance of discussing crime in the work of the Institute for Social Research of the Frankfurt University. Then, the "Fragment of a theory of the criminal" is analyzed in the light of the concepts of Enlightenment and of mimesis. The idea of the criminal as a sick person is considered an ideological construction, therefore typical of the bourgeoisie society, and it does not find rational justification in a monopolist society. Mimesis is considered the key concept for the understanding of the criminal as a sick person and it explains the changes faced by the penitentiary system in the post-fascist society.
\end{abstract}

Keywords: crime; mimesis; frankfurt school; criminal

\section{A questão do criminoso e a contribuição do Instituto de Pesquisa Social da Universidade de Frankfurt}

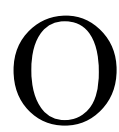
pensamento de Theodor Adorno e Max Horkheimer a respeito da pena de prisão é raramente considerado na literatura em língua portuguesa. De fato, esses autores pronunciaram-se apenas marginalmente sobre o tema, o que pode ser devido ao momento histórico vivido por esta geração da Escola de Frankfurt, em que a prisão aparecia como uma instituição auto-evidente, raramente sendo questionada em seus fundamentos (Garland, 2001). Foi apenas a partir da década de 1960 que as transformações promovidas no funcionamento prisional a partir do século XIX começaram a ser alvos de críticas que atingiram o centro das reflexões sobre a vida social, surgindo de todos os lados, inclusive do próprio establishment do controle criminal, e assumiram a forma de um profundo impulso desestruturante sobre este sistema (Cohen, 2001). O regime de verdade que o sistema penal produziu passou a ser alvo de suspeitas e ceticismo, e este sistema passou, então, a ser considerado como um mal tão grande quanto o próprio crime que ele procurava combater.

Mas, antecipando este momento de questionamento do sistema penal e penitenciário, em 1939 foi lançado um livro, sob patrocínio do Instituto de Pesquisa Social da Universidade de Frankfurt, do qual Max Horkheimer havia acabado de ser nomeado o novo diretor, chamado Punishment and social structure, escrito por Rusche e Kirchheimer (1939/2003), que, ao ser relançado em 1968, acabou por se tornar um clássico dos estudos penitenciários e inspirou toda uma geração de pensadores a debater o tema da punição. As teses presentes neste texto podem ser sumarizadas da seguinte maneira: a punição não deve ser vista como algo de socialmente universal, como faz Durkheim, mas como um fenômeno historicamente específico que apenas aparece em formas particulares, concretas. Não se pode falar em punição como algo abstrato, mas apenas em sistemas concretos de punição. O elemento determinante para explicar o surgimento destes sistemas punitivos é o modo de produção, e cada modo de produção descobre os métodos punitivos que correspondem a 
suas relações de produção. Além disso, as instituições penais não devem ser vistas separadamente em relação a outras instituições sociais, mesmo não-penais, como as fábricas, hospitais e asilos. A punição, fundamentalmente, não deve ser vista como uma resposta ao crime, mas como fruto da luta de classes entre proprietários e não-proprietários dos meios de produção, luta que é travada principalmente em torno do mercado de trabalho. A percepção socialmente compartilhada de que a punição beneficia a sociedade como um todo é, assim, uma distorção ideológica que mascara o caráter real da punição como expressão da luta de classes. Há uma relação, portanto, entre formas de punição, mudanças sociais, políticas e econômicas, e a ideologia penal (Garland, 2001; Hester \& Eglin, 1996; Rusche \& Kirchheimer, 1939/2003). Para os autores, de forma geral, as mudanças no mercado de trabalho apresentam relação com as mudanças nos métodos punitivos, principalmente pelo fato de que, para que as prisões mantenham seu papel de dissuasão criminal, suas condições devem ser piores que aquelas encontradas no mercado de trabalho. Assim, quando a oferta de força de trabalho aumenta, fazendo cair o salário e reduzindo o nível de vida da população, as condições nas prisões devem também se tornar piores, como forma de manter a função dissuasória da prisão. A correlação estrita entre fenômenos punitivos e processos econômicos fez posteriormente recair sobre este livro o anátema de "reducionista" e fez surgir uma série de estudos que procuraram esmiuçar a relação entre o aparato penal e a ideologia penal. Mas não é um acaso que este livro pareça antecipar algumas das idéias que Foucault vai defender no seu Vigiar e punir (Foucault, 1975/1991). Numa das poucas referências a literatura secundária presentes no texto, Foucault qualifica de "le grand livre" o trabalho de Rusche e Kirchheimer (Foucault, 1975/2004), e é significativo que esta referência tenha sido colocada na mesma seção em que são apresentadas as principais teses do trabalho de Foucault (Melossi, 2003).

Punishment and social structure (Rusche \& Kirchheimer, 1939/2003) teve um significado especial na história do Instituto de Pesquisa Social da Universidade de Frankfurt. Quando, em 1934, após o golpe de Hitler, as lideranças do Instituto começaram a sondar autoridades acadêmicas estadunidenses com o objetivo de transferir para aquele país as suas atividades, tornou-se premente a necessidade do Instituto de publicar textos em inglês. Georg Rusche, que havia publicado um artigo em 1930 (Melossi, 2003) contendo as idéias básicas do que viria a ser Punishment and social structure, foi comissionado pelo Instituto para desenvolver suas idéias em formato de livro, tendo publicado um artigo em $1933 \mathrm{em}$ que desenvolvia partes substanciais da futura obra (Melossi, 2003). Em 1934, Horkheimer sugeriu que ele traduzisse seu texto para o inglês e que esta fosse a primeira publicação nesta língua do que viria a ser o Instituto Internacional de Pesquisa Social, localizado agora na Universidade de Columbia, fato que indica a importância que Horkheimer atribuiu a este trabalho. Apesar das inúmeras desavenças entre Horkheimer e Rusche, que atrasaram em seis anos a publicação da obra, esta foi de fato a primeira publicação em inglês do Instituto, sendo prefaciada por Horkheimer, que a considerou uma obra "estreitamente ligada ao campo de investigação que o Instituto escolheu, ou seja, a inter-relação entre as várias esferas sociais" (Horkheimer, 1939/2003, p. li), especificamente, no caso deste trabalho, entre punição e mercado de trabalho.

Podemos afirmar, por conseqüência, que os estudos penais tiveram grande importância na história do Instituto de Pesquisa Social da Universidade de Frankfurt, e, se a iminência da guerra tornou este um assunto secundário no cenário científico, isso não significa que ele tenha perdido importância para o Instituto. Em Dialética do esclarecimento, Adorno e Horkheimer (1944/1986a) fazem constar um fragmento dedicado ao criminoso e às formas de punição ao crime. Mas as discussões em língua portuguesa sobre crime e prisão somente mencionam este fragmento marginalmente e, apesar disso, ele permite valiosos insights, mesmo quando se procura estudar temas bastante atuais, como a privatização prisional (ver, como exemplo, Minhoto, 2002). Parece-nos importante dedicar atenção à leitura deste fragmento e à questão central que ele apresenta, que é a relação entre crime e mimese, seja por sua atualidade, seja por sua importância histórica. Vale lembrar que a importância de Foucault para a difusão e o resgate do pensamento frankfurtiano (DeroucheGurcel, 1986/2002; Wiggershaus, 1986/2002) nos permite ver ecos, tanto explícitos da obra de Rusche e Kirchheimer (1939/2003), quanto implícitos, provenientes deste fragmento, neste autor que é hoje considerado a principal referência nesta área de estudos.

O objetivo deste trabalho é, assim, acompanhar o pensamento de Adorno e Horkheimer na questão do criminoso e de seu castigo, a pena de prisão, como parte do movimento total da sociedade em direção a uma economia de mercado e, posteriormente, a uma sociedade totalmente administrada de economia monopolista. Através do "Fragmento de uma teoria do criminoso" (Adorno \& Horkheimer, 1944/1986c), que aqui se procurará interpretar à luz de "O conceito de esclarecimento" (Adorno \& Horkheimer, 1944/1986d) e de "Elementos do antisemitismo" (Adorno \& Horkheimer, 1944/1986b), é possível mostrar a verdade histórica da idéia do criminoso como doente, verdade que comportava contradição, falsidade, e por isso pode ser considerada ideológica, mas que, após o fascismo, deve ser reconsiderada em seu caráter de mentira manifesta. Sobre este problema, privilegiaremos a discussão a respeito da relação entre a mimese e o crime. Além disso, este fragmento permite compreender o papel das penitenciárias no movimento histórico de constituição do capitalismo culminando com o momento em que elas já são dispensáveis na reprodução da sociedade do planejamento total.

\section{Mimese e crime no "Fragmento de uma teoria do criminoso"}

O "Fragmento", mesmo como esboço provisório (Adorno \& Horkheimer, 1944/1986e), pode ser relacionado ao conjunto do pensamento expresso pelos autores em outros textos. Este esboço traz a referência ao desenvolvimento histórico da pena de prisão até sua culminação numa sociedade que já pode dispensála. Tal desenvolvimento encontra-se expresso na divisão do próprio texto. Formado por quatro parágrafos, o texto discute a evolução das casas de detenção e correção como partes de um 
movimento global da sociedade. O primeiro parágrafo retrata o ambiente carcerário como imagem do mundo do trabalho burguês, fruto de uma sociedade na qual a necessidade de força de trabalho era crescente, fazendo uma crítica à concepção de que a existência das penitenciárias se justifica pela necessidade de isolar ou regenerar o criminoso. Ele nos traz ao cerne da constituição histórica da pena de prisão como instituição burguesa. A prisão era, antes da revolução burguesa, um ato político cujo objetivo era, sobretudo, a guarda do criminoso até seu julgamento ou execução (Bitencourt, 2001). As penas na Idade Média eram penas de suplício que agiam - tinham a intenção de agir - diretamente sobre o corpo. Talvez a única exceção, como lembram os autores (Adorno \& Horkheimer, 1944/1986c), fosse o encarceramento dos infantes reais com pretensões dinásticas. Agiam sobre o corpo já que o espírito ainda não era objeto de sanção penal. As mediações espirituais, mediações surgidas das relações de troca do mercado, são ainda um objeto a ser construído, uma verdade de outra época, que agora já se encontra em regressão. O segundo e o terceiro parágrafos discutem a idéia do criminoso como doente - idéia tão cara à criminologia e à Psicologia em algumas de suas manifestações - fazendo um movimento que vai da admissão do crime como doença à constatação de que esta idéia tem seu momento histórico específico no século dezenove, não sendo possível continuar a admiti-la atualmente. O quarto parágrafo discute o crime, o criminoso e o castigo na sociedade totalmente administrada sob o fascismo.

Adorno e Horkheimer (1944/1986c) diferenciam no "Fragmento" a existência de três formas de criminoso. A primeira diz respeito àqueles que são doentes e que já estavam doentes antes de serem presos. A segunda diz respeito àqueles que agiram como qualquer pessoa agiria frente à mesma constelação de motivos. A terceira é um tipo mais cruel e ruim do que a maioria dos homens livres, assemelhando-se aos líderes fascistas. O primeiro conjunto de criminosos é o mais comum e é o que merece atenção mais detida por parte dos autores. Este conjunto é caracterizado por sua doença. O tipo psicológico deste criminoso, que no século dezenove ainda se caracterizava por sua diferenciação marcante frente ao banditismo respeitável (Adorno \& Horkheimer, 1944/1986c), era marcado pela fraqueza em destacar-se do mundo como indivíduo e estabelecer com ele uma ligação através das formas autorizadas de comunicação. A tendência que esta fraqueza representava estava profundamente arraigada no homem, desde sua proto-história biológica, e pode ser chamada de mimetismo. O mimetismo, a tendência a "perder-se em vez de impor-se ativamente no meio ambiente, a propensão a se largar, a regredir à natureza" (Adorno \& Horkheimer, 1944/1986c, p. 212), é um dos aspectos humanos mais profundamente reprimidos pela civilização. A história desta repressão pode explicar por que o criminoso devia ser encarcerado pela sociedade burguesa.

A mimese está presente nos interstícios da sociedade esclarecida que, aparentemente, a baniu, considerando-a sinal de regressão à pré-história. Em todos os momentos do desenvolvimento da mimese - com o comportamento mimético propriamente dito, com o desenvolvimento dos mitos e com o desenvolvimento da metafísica (Adorno \& Horkheimer, 1944/1986d), além da própria negação da metafísica - há um movimento contínuo de separação do indivíduo frente à natureza mas que, por desconsiderar o que o próprio indivíduo tem de natural, guarda sempre um elemento regressivo. Ou seja, a mimese está sempre presente no desenvolvimento da humanidade como algo reprimido que ameaça voltar e jogar o homem de novo no estado de barbárie do qual, com tanto sofrimento, procurou desvencilhar-se. É o próprio reconhecimento do sofrimento com que o homem diferenciou-se da natureza que traz o medo do retorno ao estágio da barbárie, e este medo já mostra o quanto o homem ainda está submetido à natureza que não consegue admitir em si mesmo.

A mimese é um traço característico dos animais em sua tentativa de proteger-se contra os perigos da natureza. Da mesma forma, é um traço humano, o que liga diretamente o mimetismo ao horror provocado pela natureza na humanidade (Adorno \& Horkheimer, 1944/1986b): “A proteção pelo susto é uma forma de mimetismo. Essas reações de contração no homem são esquemas arcaicos da autoconservação: a vida paga o tributo de sua sobrevivência assimilando-se ao que é morto" (p. 168). O mimetismo encontra-se ainda explicitado nos rituais da magia. Nesses rituais, opera-se uma intervenção na natureza, mas esta intervenção ainda não pressupõe a constituição de um ego estável (idealisticamente hipostasiado no sujeito transcendental kantiano) que se destaque frontalmente da natureza a fim de suplantá-la, reduzindo-a a conceitos abstratos.

Como a ciência, a magia visa fins, mas ela os persegue pela mimese, não pelo distanciamento progressivo em relação ao objeto. Ela não se baseia de modo algum na "onipotência dos pensamentos", que o primitivo se atribuiria segundo se diz, assim como o neurótico. (Adorno \& Horkheimer, 1944/1986d, p. 25)

$\mathrm{Na}$ magia, ocorre uma organização do mimetismo. $\mathrm{O}$ sacerdote, para interferir nos processos naturais, para afastar uma entidade ou aproximá-la, deve utilizar máscaras e gestos com os quais se assemelha ao que deve ser manipulado. O mimetismo organizado, porém, já dá mostras do que virá a ser com a exigência da desmitologização produzida pelo esclarecimento. Na magia, já há a separação entre as coisas e o mana. O mana, o "espírito que move" (Adorno \& Horkheimer, 1944/1986d, p. 29), é um eco do terror despertado pela natureza no indivíduo. O mana é a percepção do "emaranhado da natureza" em face do indivíduo (Adorno \& Horkheimer, 1944/1986d, p. 29). Ele não é, como supõe o psicologismo, uma mera projeção do indivíduo sobre a natureza. A percepção do mana diz respeito a uma percepção da natureza que exige de fato a consideração do que os objetos em geral, diferentes entre si, têm em comum. $\mathrm{Na}$ medida em que eles representam uma ameaça, eles são tratados como algo de semelhante, e por isso os autores podem afirmar que a igualdade no mana antecipa a igualdade dos objetos sob o conceito. A igualdade neste caso, porém, não pode livrar o homem do medo que sente, pois o mana, tanto quanto os deuses, representa o próprio terror petrificado. Neste sentido, por ser uma representação do terror, o mana é algo de tautológico. Tendo como objetivo livrar o homem do medo, o mana repõe o medo no homem por ser a própria representação cristalizada 
do medo. Ao ver no conhecido o desconhecido, o homem expressava sua angústia e seu medo frente à natureza. Esta angústia será intensificada no mundo mítico e posteriormente, com o desenvolvimento do esclarecimento, ao se processar o caminho contrário, identificando-se o desconhecido com o conhecido como forma de apaziguar o medo.

Quando Homero organiza os mitos gregos, ele já o faz a partir daquilo que os próprios mitos possuem de esclarecedor e que pode ser identificado através da existência do mana, e quando Platão bane os mitos, os mitos já haviam caído de antemão pela organização homérica. $\mathrm{O}$ caminho percorrido pela civilização que procura se livrar dos mitos desenvolvendo seu espírito esclarecido é um caminho no qual nenhum passo se dá sem que tenha sido antes preparado pelo próprio espírito esclarecido, como se cada passo fosse dialeticamente preparado pelas contradições do próprio desenvolvimento da civilização. É assim que o banimento da mimese aparece como uma exigência da própria natureza frente ao humano, e esta exigência vai desembocar na necessidade de segregar e individualizar o homem preso. Em Homero e entre os judeus, a imitação já está proscrita, bem como o princípio da magia de influenciar a natureza pela assimilação. Passa-se, nos dois casos, à exigência do trabalho como forma de dominar a natureza. E o trabalho tem como elemento paralelo o sofrimento. É através do sofrimento, da renúncia a seguir o curso natural, que se forma o indivíduo. O trabalho e o sofrimento são elementos constitutivos, em oposição à mimese, da individualidade que se consolida com a sociedade burguesa.

Como lembram Adorno e Horkheimer (1944/1986a), sofrimento e trabalho só podem ser compreendidos dentro de uma sociedade já desigual, onde há a dominação e a violência. É a coerção social dos dominadores frente aos seus descendentes e subordinados e, atualmente, da sociedade toda sobre o desenvolvimento infantil, que consolida a identidade e impede o indivíduo de entregar-se aos prazeres e à imitação (Adorno \& Horkheimer, 1944/1986b). O mimetismo, que lembra nossa herança pré-histórica, ameaça sempre reaparecer ali mesmo onde foi reprimido, através de um retorno a uma imaginária felicidade passada. Entre outras coisas, é esta imagem de felicidade que não pode ser tolerada pelo indivíduo forjado no sofrimento, e esta intolerância mostra, também ela, que o mimetismo é uma força ainda presente no homem. Em Homero, esta ligação já está estabelecida:

Esse entrelaçamento de mito, dominação e trabalho está conservado em uma das narrativas de Homero. (...) A sedução que [as Sereias] exercem é a de se deixar perder no que passou. Mas o herói a quem se destina a sedução emancipou-se com o sofrimento. Nos perigos mortais que teve de arrostar, foi dando têmpera à unidade de sua própria vida e à identidade da pessoa. (Adorno \& Horkheimer, 1944/1986d, p. 43)

Apesar de esta ligação já estar presente na história antiga da civilização, foi na sociedade burguesa que a intolerância à mimese se intensificou. É com a burguesia que se opera uma tentativa de abandonar ao esquecimento a herança mimética da humanidade, transformando os comportamentos imitativos em tabus. Justamente o que parece mais estranho ao homem é aquilo que se torna vergonhoso, mas, na verdade, é bastante familiar (Adorno \& Horkheimer, 1944/1986b). Na sociedade burguesa, o trabalho ocupa o lugar da mimese, tornando os prazeres algo proibido. Esta sociedade não tolera a atitude do criminoso. Entregando-se aos prazeres, o criminoso adota uma alternativa mais prazerosa ao trabalho exigido pela sociedade e, por sua atitude, lembra à própria sociedade sua herança esquecida. A doença que os criminosos mostram é a doença do indivíduo que, com um eu mais fraco, menos capaz de opor sua resistência ao fluxo da natureza e, por causa disso, opositor do progresso inflexível (Adorno \& Horkheimer, 1944/1986c), traz à tona aquilo mesmo que não pode mais ser tolerado pela civilização. Além disso, mostra aos homens a própria imagem daquilo que poderiam ser caso o esclarecimento não tivesse imbricado em si o germe da regressão da civilização. Quer dizer, a imagem da felicidade que já seria atingível dado o avanço técnico da civilização, mas é negada pela própria constituição da sociedade, vem à tona com a figura do criminoso. Por isso, ele desperta o ódio das pessoas. A construção das penitenciárias tem, assim, esta dupla razão: além de forçar os criminosos a serem os indivíduos em que não conseguiram se transformar do lado de fora - indivíduos isolados do mundo, indivíduos que se separassem do objeto como sujeitos, no sentido kantiano, ou mônadas, no sentido de Leibniz -, as penitenciárias são também a imagem potencializada do mundo burguês. Neste último sentido, a existência das penitenciárias é produto do ódio que os homens sentem contra as exigências da sociedade burguesa, ódio que toma como objeto aqueles que, justamente, se opõem às exigências da própria sociedade. Ao se afastarem das exigências da sociedade que, de qualquer forma, já não deveriam ser mais necessárias, os criminosos mostram uma imagem do que todos poderiam ser, e isso justamente é intolerável. É como símbolo deste ódio que os homens constroem as penitenciárias (Adorno \& Horkheimer, 1944/1986c). Se, por sua própria constituição, os criminosos não podem se adaptar a esta sociedade, que sejam forçados à adaptação através da maior violência possível.

Aqui, o preconceito contra os criminosos e contra os judeus se entrelaça. Há, sem dúvida, diferenças importantes entre os dois grupos. O preconceito contra os criminosos tem seu auge durante a sociedade burguesa de economia de mercado e o preconceito contra os judeus intensifica-se com o fim desta sociedade. A razão para isso está contida na diferença entre os dois grupos. Como alvos de preconceito, as características reais destes grupos têm pouca importância, pois o preconceito baseia-se numa falsa projeção, que desemboca na paranóia (Adorno \& Horkheimer, 1944/1986b). Mesmo assim, vale lembrar que os judeus apresentam à civilização esclarecida a imagem daqueles que foram os primeiros a banir o mimetismo, ou seja, instaurando a necessidade da diferenciação e do trabalho, justamente a herança que desperta o ódio das pessoas; e, além disso, os judeus, ao contrário do que acontecia na Europa na era fascista, conservaram em seus rituais o próprio mimetismo, conseguindo manter dele a "memória expiatória" (Adorno \& Horkheimer, 1944/1986b, p. 174) sem recair pelo símbolo na mitologia. Por isso, eles eram considerados pela civilização como mais avançados, mas este avanço se voltava contra eles justamente porque a civilização não tolerava a diferença que lhes 
outorgava maior equilíbrio: "É por isso que são considerados pela civilização avançada como atrasados e muito avançados, como semelhantes e diferentes, inteligentes e estúpidos" (Adorno \& Horkheimer, 1944/1986b, p. 174). Enquanto os judeus eram os portadores da civilização, os criminosos eram portadores daquilo que lembrava a regressão à barbárie, lembrava o tempo de maior indiferenciação frente ao objeto, que despertava o temor na população. O mimetismo que os fazia resistir ao trabalho e à constituição de uma rígida individualidade era identificado como a própria antítese do esforço civilizatório. Assim, parece compreensível que os criminosos fossem mais perseguidos no momento em que a civilização mais procurava se afirmar e os judeus, no momento da desagregação da sociedade burguesa. Mas, se observarmos a razão das perseguições, veremos que são muito parecidas. Como os criminosos, os judeus também eram perseguidos pelo que se via neles de mimetismo, "os gestos contagiosos dos contatos diretos reprimidos pela civilização: tocar, aconchegar-se, aplacar, induzir" (Adorno \& Horkheimer, 1944/1986b, p. 170). E, característica fundamental desta sociedade, a perseguição se dá a despeito das características reais do grupo perseguido: "Pouco importa se os judeus realmente ainda tenham como indivíduos esses traços miméticos que provocam uma infecção maligna, ou se esses traços lhes são apenas imputados" (Adorno \& Horkheimer, 1944/1986b, p. 173). A perseguição aos judeus e a perseguição aos criminosos se faz sob o signo do mesmo temor irracional à barbárie que gera a própria barbárie no seio da civilização. Considerar o medo e o ódio ao criminoso através do medo ao mimetismo é considerar os próprios limites da civilização, na medida em que aquilo que é perseguido no criminoso tem importância capital no progresso do esclarecimento: "Um vício semelhante atravessa tudo o que se opõe ao progresso inflexível, desde o crime, que é um atalho evitando as formas atuais de trabalho, até a obra de arte sublime" (Adorno \& Horkheimer, 1944/1986c, p. 212). O temor à entrega mimética traz como conseqüência a irmanação entre criminosos $\mathrm{e}$ artistas: "A moleza com respeito às coisas, sem a qual não existe a arte, não está tão afastada da violência crispada do criminoso" (Adorno \& Horkheimer, 1944/1986c, p. 212).

A afirmação de que o criminoso é um doente, feita pela sociedade burguesa do século XIX, pode ser mais bem caracterizada como uma afirmação ideológica. Por ideologia, entenda-se um objeto que está $n a$ História e que, portanto, resiste à cristalização a-histórica com que algumas correntes do marxismo pretendem aprisioná-lo. A ideologia tem um caráter histórico na medida em que, como foi celebrizada pelos estudiosos marxistas, refere-se especificamente à sociedade burguesa. A afirmação de que o criminoso é um doente mostra-se ideológica na sociedade burguesa porque, nesta afirmação, estão imbricados um elemento de verdade e um elemento de falsidade (Horkheimer \& Adorno, 1956/1973b). Aliás, os próprios autores enfatizam esse caráter histórico do crime ao dizerem que "enquanto os criminosos eram doentes, como no século dezenove, a prisão representou o inverso de sua fraqueza" (Adorno \& Horkheimer, 1944/1986c, p. 212 [grifo meu]). Dizer que esta afirmação é ideológica implica considerar que partes da afirmação são verdadeiras. $\mathrm{O}$ papel da ideologia na sociedade burguesa é justificar os aspectos percebidos como problemáticos na sociedade. Como justificação, a ideologia é, ao mesmo tempo, a afirmação de uma verdade tem, portanto um componente racional - e uma falsidade, na medida em que ignora os componentes sociais e históricos da verdade. A civilização de fato se construiu sobre uma repressão a reações corporais que constitui o cerne do ego. $\mathrm{O}$ ego que investe contra a natureza para dominá-la possibilitou que a dominação, na sociedade burguesa, se fizesse por intermédio da razão. Uma dominação mediada, exercida através da cultura, que substitui a natureza na violência contra o homem, já contém a possibilidade de superar a dominação. Isso ocorre porque a própria mediação do espírito, o próprio pensamento, ao se tornar instrumento da dominação, torna-se independente dela e acessível a todos. A objetificação do pensamento outorga-lhe autonomia e suaviza o caráter imediato da injustiça econômica. A dominação da qual surgiu o pensamento nada pode contra a própria autonomização do pensamento, que aparece como o servo "que o senhor não pode deter ao seu bel-prazer" (Adorno \& Horkheimer, 1944/1986d, p. 48). O pensamento assim destacado pode servir de instrumento para a crítica da própria dominação. $\mathrm{O}$ movimento pelo qual o ego se destaca frente à natureza e o movimento correspondente pelo qual o pensamento se destaca da dominação que o produziu podem levar, dialeticamente, a uma superação da própria dominação e da cisão entre o sujeito e o objeto. O movimento final pode indicar uma esperança de liberdade. As tendências regressivas da civilização, porém, ameaçam este processo e trazem à tona o perigo da barbárie. A aspiração que originou a Cultura, a proteção do homem frente aos perigos da natureza, se vê ameaçada por tudo aquilo que se opõe ao progresso civilizatório. O criminoso, como o artista, representam uma ameaça na medida em que portam como estigma o abandono da organização egóica frente ao movimento da natureza. Neste sentido, podem ser vistos como portadores da barbárie. Esta intenção parece estar sendo visada pela citação na qual os autores argumentam que a pena de prisão atua não sobre o corpo, mas sobre a alma. Mas este elemento de verdade tem como contrapartida a ignorância frente às tendências regressivas que estão presentes na própria perseguição a estes grupos. No momento em que a civilização se reafirma aprisionando os criminosos, ela não só exerce pelo ódio a dominação contra a qual se ergueu, mas se impede de ver o que há de progressivo nas pessoas que persegue, que é o reconhecimento da felicidade que já poderia ter sido alcançada. A economia burguesa do século XIX já operava a partir de um exército de reserva de mão-deobra que permitia notar a ausência de necessidade da execução compulsiva do trabalho. Textos como o Direito à preguiça (Lafargue, 1880/1977) já davam conta de que a sociedade do trabalho podia dar lugar a uma sociedade, pelo menos, em que o tempo livre fosse muito maior para uma parte significativa da população. Esta tendência só fez aumentar ao longo do século XX e é retratada nas discussões atuais sobre a centralidade ou nãocentralidade do mundo do trabalho na sociedade contemporânea (Antunes, 1995; Gorz, 1987; Offe, 1989). A constituição de um sistema penitenciário que obrigava os homens à disciplina monótona do trabalho, por meio da execução repetitiva de trabalhos sem sentido, representando triste e radicalmente o mundo burguês, portanto, não era uma necessidade econômica da sociedade. É possível que esta necessidade crescente de força 
de trabalho à qual se referem os autores como fundamento para o surgimento da pena de prisão, bastante evidente no século dezesseis, já tivesse sido superada no século dezenove, em que, mesmo assim, ainda se pode falar de uma "doença" criminal. Esta possibilidade permite notar a falácia que está permeando a afirmação da necessidade de um sistema penitenciário. Como imagem do autocontrole necessário para o domínio esclarecido da natureza, a penitenciária era dispensável no século XIX. Assim, nesse momento, a perseguição aos criminosos comuns já era portadora da própria regressão contra a qual queria defender a sociedade. $\mathrm{O}$ aprisionamento mostrava o caráter compulsivo do trabalho nesta sociedade que já podia dispensar as longas horas à frente das máquinas. Quanto ao aspecto de falseamento da afirmação ideológica do criminoso como doente, devemos ressaltar que a autoconsciência da civilização com relação aos reais motivos de seu medo é que poderia fazer avançar a civilização num rumo em que ela própria se superasse, se ligada a uma práxis revolucionária, e não a tentativa de fazer deter o movimento da sociedade (Horkheimer \& Adorno, 1956/1973a) através da perseguição aos seus membros. Quando ainda havia uma mediação espiritual a ser defendida contra a barbárie, portanto, os criminosos podiam ser vistos ideologicamente como doentes. Como ameaça a esta mediação, eles traziam a possibilidade de desintegração e deviam, assim, ser objeto da ação institucional dos presídios. Frente a este conjunto, ainda se podia debater sobre a irracionalidade presente nesta imagem dos criminosos na tentativa de superá-la em prol de uma autoconsciência dos reais motivos do medo à sobrevivência da mimese no seio da civilização.

Isso tudo se transforma, porém, com o advento do fascismo. $\mathrm{O}$ aniquilamento da economia de mercado substituída pelo monopólio direto faz ceder a necessidade das mediações, inclusive espirituais. Com a ausência da permuta de equivalentes que constituía a essência do mercado de trocas, a percepção da justiça transforma-se. A justiça como troca de equivalentes era parte constitutiva da ideologia burguesa (Adorno \& Horkheimer, 1944/1986d) e, a rigor, não se pode falar em ideologia quando regem relações simples e imediatas de poder (Horkheimer \& Adorno, 1956/1973b). O fascismo não tem necessidade, na sua assim chamada "ideologia", de qualquer elemento de racionalidade. Portanto, não se pode falar em ideologia fascista. O positivismo já havia preparado o campo para isso ao eliminar o sujeito transcendental, última instância intermediária entre a ação individual e a norma social, sujeito este que se volatiliza ao mesmo tempo frente à indeterminação das regras do jogo na sociedade (Adorno \& Horkheimer, 1944/1986d). Com o fascismo, a fronteira entre o banditismo legal e ilegal se torna fluida e, como conseqüência, os tipos psicológicos se confundem. Só o poder distingue o fascista do criminoso (Adorno \& Horkheimer, 1944/1986c). Ao afirmarem isso, os autores mostram a relação intrínseca entre sistema econômico e personalidade que permite considerar a psique humana como tendo um caráter historicamente definido (Adorno et. al., 1950). Esta aproximação entre os criminosos e os fascistas merece uma consideração, na medida em que se percebe que não é a qualquer criminoso que os autores se referem. A comparação, neste caso, parece estar sendo feita com o terceiro tipo criminal, o tipo mais cruel que a maioria das pessoas, e que se refere à personalidade perversa. Ao menos, é somente este último tipo que é aproximado do líder fascista no texto. O direito, que absorve a justiça sob o esclarecimento (Adorno \& Horkheimer, 1944/1986d) e que constitui uma das mediações espirituais, torna-se o governo direto, o puro terror, perdendo até mesmo o caráter de aparência que sempre havia tido sob o mercado. Repetindo o movimento do esclarecimento pelo qual os estágios anteriores são renegados como ultrapassados e míticos ou metafísicos (que pode ser apreendido em Adorno \& Horkheimer, 1944/1986d), o fascismo considera a própria idéia do crime e do castigo como resquícios supersticiosos e parte para a aniquilação dos recalcitrantes. Isso mostra que a prisão, como parte da sociedade burguesa, com sua intenção de atacar a alma do criminoso, era menos regressiva que a atuação direta de extermínio perpetrada pelo fascismo. $\mathrm{Na}$ sociedade fascista, já não cabe mais falar no criminoso como doente. É a própria sociedade que adota a alucinação como norma e faz a mentira ter um caráter tão espesso que rompê-la e ver a verdade produz a impressão de loucura. Na sociedade totalmente administrada, a coerção social sobre o indivíduo (ou a coerção do universal sobre o particular) é o último resquício do contrato social, que ainda permitia a existência de indivíduos. Hoje, a pressão e o controle se exercem tão estreitamente sobre o indivíduo, que já não há espaço para reações individuais. Compramos, vestimos e pensamos o que somos obrigados pela indústria cultural e outros meios de coerção social. E, paradoxalmente, a sociedade contemporânea, que esmaga o indivíduo, é a que mais produz pessoas individualistas. Ou seja, quanto menos indivíduos existem, maior é o individualismo (Horkheimer \& Adorno, 1956/1973c). A idéia de transformar criminosos em indivíduos burgueses, portanto, que era diretamente relacionada à pena de prisão como instrumento para o aumento da força-de-trabalho, torna-se anacrônica sob o fascismo. Mesmo porque, frente ao progresso técnico, a classe dominante já não tem necessidade de uma grande quantidade de força-de-trabalho para a reprodução da sociedade, adestrando o pessoal excedente para ocupar a posição de guardas adicionais do sistema (Adorno \& Horkheimer, 1944/1986d). A pena de prisão burguesa ainda continha uma pretensão, mesmo que ideológica, de transformar os criminosos em indivíduos. Sob a sociedade do planejamento total, isso não é mais necessário. O próprio indivíduo torna-se supérfluo, sendo esmagado pela corrosiva coerção social. A socialização que já não se faz sob a família, mas se faz diretamente como massa pelos meios de comunicação social, impede a constituição do indivíduo. Ao lado disso, surgem protestos espontâneos e inconscientes na base social contra a pressão e a frieza da sociedade, que têm a intenção de oferecer ao indivíduo solidariedade e alguns esquemas de identificação, sendo paradigma deste processo as gangues de jovens (Horkheimer \& Adorno, 1956/1973d). É no desvio que pode aparecer, ainda que de forma incipiente, o indivíduo. Esta inversão frente à sociedade burguesa marca o crime como um fenômeno distinto do estudado pelos clássicos do século dezenove, e o sistema penitenciário como preenchendo uma função na sociedade distinta daquela que exercia quando surgiu. Se continuamos a aceitar o argumento segundo o qual a pena de prisão é incontornável, já não o fazemos sob a expectativa de que 
ela possa impedir um retorno à barbárie. Esta aceitação tácita se faz por uma adesão aparentemente imediata a um ideal que aparece claramente como mentiroso. Quando o poder se exerce diretamente, não há espaço para a racionalidade no discurso da dominação. Desta forma, não é possível realizar uma crítica às alegações do poder. No que se refere ao sistema penitenciário, seu fracasso está evidente. Não se pode mais justificar a existência dessas instituições com base em alegações racionais. Resta compreender exatamente por que elas ainda sobrevivem e por que parecem se tornar, a despeito de todas as evidências, cada vez mais necessárias.

\section{Referências}

Adorno, T. W., Frenkel-Brunswik, E., Levinson, D. J., \& Sanford, R. N. (1950). The authoritarian personality. Studies in prejudice. Nova York: Harper.

Adorno, T. W., \& Horkheimer, M. (1986a). Dialética do esclarecimento. Fragmentos filosóficos (G. A. de Almeida, Trad.). Rio de Janeiro: Jorge Zahar. (Texto original publicado em 1944)

Adorno, T. W., \& Horkheimer, M. (1986b). Elementos do anti-semitismo: limites do esclarecimento. In Dialética do esclarecimento. Fragmentos filosóficos (pp. 157-194, G. A. de Almeida, Trad.). Rio de Janeiro: Jorge Zahar. (Texto original publicado em 1944)

Adorno, T. W., \& Horkheimer, M. (1986c). Fragmento de uma teoria do criminoso. In Dialética do esclarecimento. Fragmentos filosóficos (pp. 210-213, G. A. de Almeida, Trad.). Rio de Janeiro: Jorge Zahar. (Texto original publicado em 1944)

Adorno, T. W., \& Horkheimer, M. (1986d). O conceito de esclarecimento. In Dialética do esclarecimento. Fragmentos filosóficos (pp. 19-52, G. A. de Almeida, Trad.). Rio de Janeiro: Jorge Zahar. (Texto original publicado em 1944)

Adorno, T. W., \& Horkheimer, M. (1986e). Prefácio. In Dialética do esclarecimento. Fragmentos filosóficos (pp. 11-17, G. A. de Almeida, Trad.). Rio de Janeiro: Jorge Zahar. (Texto original publicado em 1944)

Antunes, R. (1995). Adeus ao trabalho? Ensaio sobre as metamorfoses e a centralidade do mundo do trabalho. São Paulo: Cortez/Editora da Unicamp.

Bitencourt, C. R. (2001). Falência da pena de prisão. Causas e alternativas $\left(2^{\mathrm{a}}\right.$ ed.). São Paulo: Saraiva.

Cohen, S. (2001). Visions of social control. Malden: Polity Press/Blackwell.
Derouche-Gurcel, L. (2002). Prefácio da tradutora da edição francesa. In R. Wiggershaus (Org.), A Escola de Frankfurt. História, desenvolvimento teórico, significação política (pp. 13-29; V. A. Harvey, Trad.). Rio de Janeiro: DIFEL. (Texto original publicado em 1986)

Foucault, M. (1991). Vigiar e punir. História da violência nas prisões ( $9^{\mathrm{a}}$ ed., L. M. P. Vassallo, Trad.). Petrópolis: Vozes. (Texto original publicado em 1975)

Foucault, M. (2004). Surveiller et punir. Naissance de la prison. Paris: Gallimard. (Texto original publicado em 1975)

Garland, D. (2001). Punishment and modern society: A study in social theory. Chicago: The University of Chicago Press.

Gorz, A. (1987). Adeus ao proletariado: para além do socialismo ( $2^{\mathrm{a}}$ ed., A. R. Vianna e S. G. de Paulo, Trad.). Rio de Janeiro: Forense.

Hester, S., \& Eglin, P. (1996). A sociology of crime. Londres: Routledge.

Horkheimer, M. (2003). Preface. In G. Rusche \& O. Kirchheimer (Orgs.), Punishment and social structure (pp. li-lii). New Brunswick: Transaction. (Texto original publicado em 1939)

Horkheimer, M., \& Adorno, T. W. (1973a). Cultura e civilização. In Temas básicos da sociologia (pp. 93-104, A. Cabral, Trad.). São Paulo: Cultrix. (Texto original publicado em 1956)

Horkheimer, M., \& Adorno, T. W. (1973b). Ideologia. In Temas básicos da sociologia (pp. 184-205, A. Cabral, Trad.). São Paulo: Cultrix. (Texto original publicado em 1956)

Horkheimer, M., \& Adorno, T. W. (1973c). Indivíduo. In Temas básicos da sociologia (pp. 45-60, A. Cabral, Trad.). São Paulo: Cultrix. (Texto original publicado em 1956)

Horkheimer, M., \& Adorno, T. W. (1973d). O grupo. In Temas básicos da sociologia (pp. 61-77, A. Cabral, Trad.). São Paulo: Cultrix. (Texto original publicado em 1956)

Lafargue, P. (1977). Direito à preguiça e outros textos. Lisboa: Estampa. (Texto original publicado em 1880)

Melossi, D. (2003). Transaction introduction. In G. Rusche \& O. Kirchheimer (Orgs.), Punishment and social structure (pp. ix-xlv). New Brunswick: Transaction.

Minhoto, L. D. (2002). As prisões do mercado. Lua Nova, s/v (55-56), 133154.

Offe, C. (1989). Trabalho: a categoria-chave da Sociologia? Revista Brasileira de Ciências Sociais, 10(4), 5-20.

Rusche, G., \& Kirchheimer, O. (2003). Punishment and social structure. New Brunswick: Transaction. (Texto original publicado em 1939)

Wiggershaus, R. (2002). A Escola de Frankfurt. História, desenvolvimento teórico significação política (V. A. Harvey, Trad.). Rio de Janeiro: DIFEL. (Texto original publicado em 1986)

Gustavo Martineli Massola, doutor em Psicologia Social pelo Instituto de Psicologia da Universidade de São Paulo, é pesquisador no Laboratório de Psicologia Socioambiental e Intervenção da mesma instituição (LAPSI/IPUSP). Endereço para correspondência: Rua Campos Salles, 214 (Santa Terezinha); São Bernardo do Campo, SP; CEP: 09770-190. Tel./Fax: (11) 4330-6534. E-mail: gsmartineli@yahoo.com.br 